Ballestero S., A. (2012). Transparency Short-Circuited: Laughter and Numbers in Costa Rican Water Politics. PoLAR: Political and Legal Anthropology Review, 35(2), 223-241. doi:10.1111/j.1555-2934.2012.01200.x

\title{
Transparency Short-Circuited: Laughter and Numbers in Costa Rican Water Politics
}

\author{
Andrea S. Ballestero, Rice University [ORCID: 0000-0001-7692-0514]
}

\begin{abstract}
Between 2006 and 2009, a group of Costa Rican NGOs, a Spanish aid agency, and local residents were entangled in the pursuit of transparency as a means to allocate funding for their "human right to water" project initiatives. Designed as a series of pedagogical activities to "build" local knowledge about water management, the aid agency conditioned their funding to the honest and correct implementation of the project as revealed by a system of indicators. Against orthodoxy, project leaders were put in charge of designing and implementing the auditing system, an arrangement that short-circuited the foundational separation between observers and observed that is customary in transparency-creation projects and gave the whole initiative an experimental quality. This article examines the building of that indicator system, my informants' own fascination with producing "speaking numbers," and the punctuated but constitutive role that laughter played in the process. I suggest that numeric indicators and laughter make the audit speak about intensity and emphasis rather than about the exclusive and discrete categories on which transparency is usually predicated. Here, the audit allowed political actors to rework the potential of water governance technologies, rather than limiting them to their explicit possibilities, in order to constitute what project participants imagine as an integral form of political agency. I argue that paying attention to the in-between process of creating the audit, before its final results are disclosed, highlights the self-referential, short-circuited, and productive uses of transparency as a political device.
\end{abstract}

Keywords: indicators; laughter; numbers; audit; knowledge; NGOs 
In 2006, the prospect of securing funding for a project to promote the recognition of water access as a human right was a priority for Joaquin and Veronica, two seasoned NGO executives working in Costa Rica. Convinced of the importance of maintaining local and public control over water resources and giving local communities stronger legal and economic arguments to participate in water policy discussions, they wrote a project proposal titled "Community Water Management Capacity-Building Program." Their formal objective, as written in the proposal's text, was to "increase knowledge and empower local community organizations following integrated water resources management principles" (Rojas Moncada and Mora Portuguez 2007:7). More broadly, however, the project was intended to increase public recognition of community-based collectives and the work they do to provide water access to more than 25 percent of Costa Rica's population. After a fruitless search for funders that [End Page 223] extended for months, Joaquin and Veronica seemingly convinced AIDE, an aid agency of the Spanish government, of the viability of their project. The long process of courting AIDE ended in 2008 when Joaquin and Veronica found themselves with a funded project, although with less financial resources than they had requested, and with an obligation to design and implement an audit system to support AIDE's public commitment to transparency as a public value.

From AIDE's perspective, the audit system would quantify the impact of their financial investment in the Central American region and document the noncorrupt use of resources by project beneficiaries. From the proponents' perspective, the audit promised much more. It was a process of intensive exploration guided by participants' own questions about their political abilities more than by the accountability standards with which AIDE was concerned. Determining "who they were and what they did" were the foundational questions that the participating NGOs wanted to answer before any transparency or accountability could be delivered. The organization and design of the audit became a self-referential experiment that, through its humorous encounters and the intricacies of the numeric indicators it produced, opened an opportunity for assembling a sense of the self that spoke to the group's curiosity about its own political potential.

This article examines the making of that audit and analyzes how indicators are used to simultaneously display the affective, bodily, and multiscalar qualities of the entity that Joaquin, Veronica, and the other NGOs in the project understand themselves to be. I argue that although it is not surprising that these dimensions are interlaced through the audit, the knowledge practices through which they are connected speak of the participants' desire for an integral depiction of their political agency. My colleagues' efforts to make themselves transparent could be taken as an instantiation of the hierarchies of capital and postcolonial aid relations in which they are inscribed (Li 2009; Murray Li 2009). In this article, however, I want to bracket that reading and instead accentuate the creativity and instrumentality with which they engaged with transparency. Their own commitment to the possibilities of the process requires me to take seriously their production of indicators not as knowledge practices devoid of politics and culture but, quite the contrary, as deeply cultural and political instruments inscribed in broader struggles for justice and rights (Merry 2011:1). As a strategic methodological move, this article privileges my colleagues' understanding of their experimental use of indicators instead of the logic of legibility and control with which funding organizations might oblige aid recipients to account for their own experience (see also Kipinis 2008). I take these NGOs' use of indicators as experimental because the resulting entity these numbers describe is not fully known until the naming 
experiment is performed. That is, the qualities of the entity that the experiment describes are only legible after the act of description and measurement has occurred (Rheinberger 1997:28).

To understand the work of indicators and the political possibilities of transparency, I ask what kinds of knowledge-work do these indicators perform? And how does that work destabilize the logics of classification and subjectivity under which aid agencies push for transparency? For my informants, the ulterior uses of the audit results [End Page 224] by the Spanish agency are relatively less important than the political opportunities that their creation afforded them. Those opportunities worked as a chance for self-overcoming (Grosz 2004:64) the subject position that in capitalist democracies is assumed to be the foundational legal and political way of being: the individual subject. Instead of merely measuring the knowledge that an individual acquires after a training event, my informants began by asking themselves what the self should be made of in the first place: how can "we" make ourselves speakable under different coordinates than the individual? Their answer became an experiment in "naming intensities that affect [the political subject], augmenting or diminishing its power to act" (Deleuze and Guattari 1987:256). Rather than using categorical distinctions, their answer focused on "continuous and relatively indivisible" (DeLanda 2002:45) properties and domains.

The qualities of the political agency and self they wanted to name required a style of thought that, despite its numeric form (as indicators), had "a more flexible exactitude" (DeLanda 2002:53). Theirs was an experiment that redirected numeric technologies to make speakable what they understand as an integral power to act. In their view, an entity is integrally rendered when all of its dimensions can be simultaneously visualized. Such an entity cannot be explained by exclusively, if only temporarily, considering one domain (such as speaking only about knowledge or individuals). To be represented, all domains and qualities need to be indexed simultaneously. Not quite a complete break with liberal ideas of the person that situate it in relation to the nation and as part of a collective (Lury 1998; MacPherson 1962; Strathern 2004), the audit, however, pushed classificatory logics for which things have to be located into one, and only one, category.

In national and international water policy circles the rhetoric of multiplicity is ubiquitous. Policy recommendations emphasize the need for multiple actors, forms of knowledge, and scales in water management. In the instrumentation of these recommendations, multiplicity is difficult to domesticate and projects often end up privileging one type of actor, knowledge, or scale. This audit was an effort to devise an epistemic instrument that would truly make multiplicity speakable by using familiar elements, but by organizing them under a logic of intensity, not exclusion. After giving some background to the creation of the project, in what follows I replicate three moments in the construction of the audit (the design, adaptation, and preliminary interpretation of the indicators) and note the contradictory, careful, and humorous tactics that turned it into a decision event where the "possibilities of the self" were shaken up and reorganized (Humphrey 2008). Each of the sections restages a new articulation, an addition of categories to the integral and multifaceted entity that my colleagues understand themselves to be when they work for water issues. [End Page 225] 


\section{Before There Was An Audit}

Joaquin and his colleagues had to spend hours thinking about how to produce an audit. Joaquin is trained as a lawyer, and he specializes in environmental law and works as the executive director of an organization I will refer to as DHAC. This organization is rather small; it has only four permanent employees, although they describe themselves as a federation of approximately 30 Central American grassroots and NGOs involved in sustainable water management and policy development. DHAC's main purpose is to lobby national and international aid and policy actors for community control of water systems (i.e., aqueducts, provision services, and so on). DHAC's slim structure and focus on lobbying instead of water infrastructure projects has yielded it a somewhat controversial reputation. Some environmental organizations contend that DHAC "uses" them to secure funding and sometimes takes credit for the results of their work.

Veronica's organization, AFCA, is also a federation but one of campesino and indigenous organizations and a much larger entity than DHAC. It was created to promote sustainable agriculture by providing direct technical assistance to farmers. Its active presence throughout Central America can be partially credited to a large grant it received from the World Bank in the early 2000s. Veronica, who is originally from Honduras, is trained as an agricultural engineer and moved to Costa Rica to work as one of AFCA's technical personnel division leaders. These two NGOs, DHAC and AFCA, frequently participated in the same water policy fora in Costa Rica and Central America. On those occasions, Joaquin and Veronica often talked about formulating and submitting a project together, but until this proposal they had only collaborated informally.

In 2008, after more than 18 months of back and forth via e-mails, exchanging documents, and Skype calls, AIDE announced its decision to fund Joaquin and Veronica's project. The text of the application they submitted depicted their affiliated organization as having great practical experience and tacit knowledge but lacking formal policy "tools" to participate in national water discussions. To fill this gap, their project proposed a series of training topics and activities that had been determined in a participatory planning workshop held back in 2006 with governmental and academic participants, and grassroots organizations. Representatives from 11 communities, a local development association, community aqueduct associations, an environmental activism grassroots NGO, a transnational Banana Plantation Workers Union, an environmental law NGO, and some residents of small rural towns produced a list of training topics. By the end of that twoday event in 2006, they had settled on negotiation skills, financial management, the human right to water, and integrated water resource management principles as topics that would help them "build capacity" to be more effective in their ongoing mobilizations for the inclusion of the human right to water in the Costa Rican constitution.

The training proposal they wrote was for three years and consisted of six workshops, a three-day regional course, three short lectures, a short digital video, and radio announcements to disseminate the idea of water access as a human right and to clarify its legal and financial implications. The organizations that selected the topics remained involved in the project, and when given the choice they favored short training events that allowed them to also fulfill the responsibilities of their daily jobs. The work most of participants did for these organizations was 
on a volunteer basis since most made their livelihoods as farmers, teachers, housewives, and small business owners. Not a fully egalitarian process, yet not a completely centralized one either, the design [End Page 226] of the project enrolled a large number of actors, events, and conversations throughout the two years of its making. AIDE's approval of US\$125,000 was bittersweet news. The proponents thought the approved funding was insufficient, and almost ridiculous, given all the activities they had planned. Yet in a situation where they did not want to reject the funding or give the impression that they were incapable of delivering results, they accepted the funding and supplement them with resources from other projects with similar objectives.

AIDE's approval of the proposal carried with it another surprise. The agency had publicly committed to making all of their projects transparent and required the joint DHAC-AFCA organization to produce a series of indicators showing how the funds were used and, most importantly, quantifying the impact the project had on the participating organizations. While recounting this history for me, Joaquin narrated his conversation with AIDE's representative in this way:

Her words were, "We are tired of putting money down for training, not seeing the results, and losing sight of where the money went. This time we want to measure the impact and destination of the money." I saw her point. Really, many times, those projects are just a waste of time and money. (San Jose, Costa Rica, June $7^{\text {th }}, 2010$ )

In a tactical move, Joaquin convinced AIDE that they did not need to hire outside consultants to design the indicators. Their organizations already had the necessary know-how to design and implement an indicator system that fulfilled AIDE's promises of transparency to the Spanish taxpayers. Furthermore, Joaquin told AIDE that his NGO colleagues in Costa Rica were genuinely interested in developing that kind of information to use in their own lobbying activities.

AIDE's acceptance of Joaquin's proposal unleashed a process in which not only auditing and evaluation objectives were merged (Gray 2002), but also, most significantly, where the roles of observers and observed were combined. Although auditing and evaluation are usually separated, in this project both were achieved using a single methodology. Joaquin, Veronica, and the other participants in the project, that is, those who according to AIDE had to be observed by the auditing gaze, were now in charge of designing the indicator system through which that gaze was going to be constituted. In this circular arrangement, they had space to elucidate not what they stood against, as so much of their activist work did, but what they thought themselves to be. The audit was turned into an exercise of self-referential naming.

\section{Step One: Designing An Answer For The Question}

Joaquin and Veronica's excitement about the possibilities of the audit grew every time they explained how they had convinced AIDE to let them take charge of the process. Besides the economic motivation to prevent project dollars from going to other actors, they were deeply 
invested in making the audit produce an "integral" picture of themselves. Joaquin explained to me that an integral depiction would counter the one-dimensional representation of water committees and local communities [End Page 227] that politicians and international aid workers made the few times they paid attention to their work. An integral picture would capture and simultaneously show their different facets and scales without forcing them to select one over another. Throughout the making of the project, I often heard Joaquin articulate this feeling by saying that if implemented this project was going to finally help them "know what they knew." He emphasized the need to know what their work accomplished, and he repeated that this audit would give them an integral vision of themselves. Since neither of them had ever used an audit instrument that produced this integral portrayal, this uncertain experiment needed to begin with the selection of a methodology that could respond to their existential questions.

As noted earlier, along with Joaquin and Veronica, participants in the project included representatives from NGOs affiliated with DHAC and AFCA. Among that larger group of participants, there was a shared view that numeric indicators were the best political instruments for this experiment. Carlos, a representative of the Banana Plantation Workers Union, eloquently explained their desire for political recognition by pointing to the limitations many grassroots organizations feel because they do not have the know-how to produce and display Excel sheets, percentages, and graphs the way that bureaucrats, consultants, and politicians do. "Once you have numbers," he told me during one of our conversations, "you can show them [the government] the value of what communities do for water management. Yes. Numbers speak" (San Jose, Costa Rica April $25^{\text {th }}$ 2009). The audit was an opportunity to create their own "speaking numbers." But their conviction that numeric indicators were the best instruments for that job did not grow out of a naïve belief in numeric objectivity or in the separation between fact and value. On the contrary, if they accomplished good speaking numbers, they could convey their particular sense of themselves as integral political actors: a move that highlights the inseparability of fact and value. These speaking numbers would tell the stories they wanted them to tell.

The uses of numbers, expected and unexpected, are not new topics in anthropology. In his study on nationalism, Benedict Anderson (1991) showed how numbers and quantification produced the fiction of the whole while providing a flexibility of use based on the seemingly neutral character of numeric figures. In his view, the key property that numbers added to political exercises, such as census making, was an aura of openness and malleability. In a similar vein, Theodore M. Porter (1995) drew attention to how numbers, a presumed sign of objectivity for policy makers and scientists, are intended as means of erasing context and securing trust among political actors within technocratic and scientific cultures. He showed how numbers are taken as constitutive of facts because they supposedly strip those facts of values. Another line of scholarship, however, has shown how numbers cannot be taken as given objects with inherent properties. From this perspective, numbers have the social and cultural conditions of their production inscribed in them: numbers are culture (Guyer 2004; Guyer et al. 2010; Latour 1990; Maurer 2005). In this body of work, numbering and quantification are understood as practical accomplishments "embodied in a collective going on in specific times and places" and not as objects waiting to be discovered (Verran 2001:220). My informants' clarity about numbers [End Page 228] as cultural accomplishments was never more evident than during the methodological discussions they held. 
After considering various alternatives, Joaquin and Veronica hired Xinia, a mutual colleague and friend from another NGO, to help them find an appropriate methodology. Xinia is an expert on participatory techniques and on CAP (conocimientos, actitudes, y prácticas; knowledge, attitudes, and practices), an evaluation and monitoring methodology used by many international organizations to measure the impact international aid projects have on participants' lives. Explicitly designed for capacity-building projects, CAP is organized around facets of the human without aggregating them into a dominant category, such as knowledge. In part, it does so by compartmentalizing types of experience in the form of variables and measuring each slice independently. As a method, CAP produces an image of the human as an entity "made of [distinct] parts accreting with other parts" (Lury 1998:19). That ethos of independent parts, however, was not embodied in the auditing project despite their selection of this methodology. The meaning of CAP was peculiar to the purpose that project participants had for the audit. Before expanding on how that purpose was enacted, let me place this project within broader trends of social commentary on transparency.

As has been well documented, transparency is a widespread political objective and technological dispositif (apparatus) (Foucault 1980; Garsten and Lindh de Montoya 2008; Hetherington 2011; Roberts 2009; West and Sanders 2003). Scholars have outlined the diverse forms taken in recent years that make the invisible visible, an epistemic project inherent to modernity (Gaonkar and McCarthy 1994; Hull 2008; Mathews 2011; Reed 1999). Visibility, in most of these accounts, is presumed to be the effect of information flow, in its material and abstract forms, between people in different social locations - between citizens and corporations and between citizens and the state (Toms 2010:4). Complementing this logic of information control, it is argued that transparency also opens spaces for responsible decision making by public officials who, thanks to these policies, become accountable (Florini 2007:5) and thereby closer to their constituencies.

Parallel to this positive outlook, the limitations of transparency as a means for more democratic action have also been well documented (Bessire 2005). Scholars have noted the ways in which NGOs conceal and misrepresent information (Burger 2010; Prat 2005), auditors transform fluid spaces into stiff quantitative accounts (Shearer 2002; Vaivio 2006), and agents struggle to identify units to be counted (Nelson 2010). Given this wealth of literature, it has become an accepted fact that transparency projects most often fail to deliver on their democratic and political promises. Precisely because of this, documenting that failure can only be a starting point to ask what, in fact, are transparency projects delivering if it is not the more just and democratic worlds they promise.

Critics and apologists of transparency alike tend to presuppose the existence of a foundational divide between those who hold information, in the form of documents, files, or their own experience, and those who want to access that information. The anthropological literature on audit cultures embodies this foundational separation. As [End Page 229] Strathern (2000) has noted, transparency as a quality of the operation of governing and knowledge-making is endorsed as an "outward sign of integrity" (2). For Chris Shore (2008), that outward revelation is mediated by external experts who interpellate people as auditees and compare their individual performance to bureaucratic benchmarks and economic targets that they also set. But with the propagation of centers of governance and sites of regulation across society, this stark divide between observers and observed has become partially blurred. New locations of power and rule 
making, including NGOs, international organizations, and certification agencies, compose multiple legalities and normative regimes where citizens, as well as private and public institutions, produce knowledge about themselves for their own consumption (Merry 2011; von Benda-Beckman et al. 2009). As a result, questions about the legitimate source of sovereignty (who governs and regulates, and who is governed and regulated) are necessarily complemented, and sometimes displaced, by the question of how to govern and how to regulate regardless of to whom sovereignty is adjudicated (Kipinis 2008; Riles 2005; Valverde 2009). In these situations, the fundamental distinction between those who observe and solicit information and those who are observed and produce information is short-circuited. Under these conditions, the utility of transparency as a political artifact for, on the one hand, creating distance between fact and value and, on the other, connecting actors with asymmetric positions and types of information, is slowly vanishing. What this short-circuited type of transparency makes explicit is the ability of indicators to create, rather than merely document, facts that are about values. For Joaquin and Veronica, for example, their transparency project is synonymous with composing an image of themselves that reveals their integrality. The technicality of numbers becomes a means to explicitly enact those political values. While technocrats might see numbers as objectivitycreation devices that render the world transparent to an external observer, the NGOs I worked with see numbers as means to constitute political projects, very much in the way that anthropologists would understand them.

In my informants' genre of transparency-creating numbers, the intricacies of naming and quantifying are strategic ways of shaping political potentials. The practices through which names are created, numbers produced, and categories constructed become sites of active sociality and experimentation. In this case, instead of following well-established ideas of the subject as a rights-bearer, numbers allow project participants to highlight the multiple dimensions involved in naming who they are. These dimensions are held next to each other through an epistemic practice that is able to emphasize their peculiarities without subsuming them to a single category. In this knowledge-making experiment, differences between dimensions should not be cancelled through homogenization (DeLanda 2002:159), as it occurs when one implicitly settles on a single category such as the community, the individual, or even the nation to describe political action.

\section{Step Two: Adapting Numbers as a Political Experiment}

In late February 2008, a short follow-up workshop took place in downtown San José, the capital city of Costa Rica, to familiarize 23 representatives of DHAC and AFCA's [End Page 230] affiliated organization with CAP, the method that Xinia, the new participant in the project, was bringing to the group. The workshop took place at the headquarters of the Federation of Voluntary Organizations in a rundown classroom with a large whiteboard and a few worn-out school tables and chairs. As the workshop began, Joaquin explained the objectives of the project and the role of the audit in it. He emphasized that through a questionnaire they would measure how participants were transformed by the training activities. Each question would draw attention to one of the CAP variables and produce an indicator represented by a percentage. Participants' responses, in the form of percentages, were then going to be compared before and after training activities to quantify the impact of the project. Joaquin continued his introduction by saying, "The method we have chosen...is the best one to tell us who we are and what we do," and he 
paused, gauging reactions to his statement. He then introduced Xinia, who began her talk with a thorough description of the differences between qualitative and quantitative research and continued with a brief history of CAP's origins in United Nation's extension projects. Next, she proceeded to the more challenging part of her explanation. "Now, we are going to get into the method itself. Remember, CAP measures three variables, so let's discuss them," she said as she moved closer to her laptop, clicked on the next slide in her PowerPoint presentation, and started reading from the projected text about the first variable:

Knowledge refers to the things that we know, the things that are common sense, but not necessarily due to having studied them. It represents the things we learn in life from our experiences, our observations, and also from studying. It is also connected to the things that we do. We can expect that if somebody knows something, he [sic] reflects, and then changes his behavior.

The second variable, actitudes, had a more complicated temporal orientation and a less precise definition,

Attitudes come from behaviors, from the ways people comport themselves. But we can have an attitude without having to take action.... Attitudes are ways of reacting to reality. We also have attitudes that are there, waiting for something to happen. An attitude is the expectation of acting in a certain way even if an event has not occurred. But we have to understand them as coming from the community, from a person's age group, from the collective, if a person is a man or a woman.

And finally the last variable, prácticas, she explained in this way,

So, if we know that knowledge is what we know, attitudes are the ways in which we react and feel about things, then practices are what?... Yes, the things that we do. The way we comport ourselves on a daily basis, constantly. Practices are repeated in time, they are normal and quotidian, we don't think much about them. [End Page 231]

Even though orderly division into discreet and independent parts is what CAP demanded, Xinia's explanation was entangled by the difficulty of keeping those discreet variables separate. In her explanation,

Attitudes are related to things that you do, even though they are dormant and are activated only when you are confronted with certain events. Knowledge relates to experience, but is also different from it, although it is derived from reflection [knowledge itself] and from action [practice].

CAP slowly became an impossible method for keeping independent variables apart. Auditing and transparency methodologies are usually wary of counting the same thing twice or including overlapping measurements because such redundancy supposedly fractures the proportional and isomorphic relation between the unit to be counted and the number that counts. In Xinia's first description of CAP, however, knowledge, attitudes, and practices had clearly overlapping, overflowing, and blurred boundaries.

After her explanation, Xinia began an exercise to help us understand the rather abstract concepts she had presented. She picked up a stack of papers and passed them out. The sheets had a selection of practice questions designed to help us recognize and classify each of the three variables we had discussed. Our task was to read each practice question, which did not relate to 
water issues in any way, and to identify which variable in the triad of knowledge-attitudespractices it corresponded to. Xinia's instructions seemed to be at odds with the fluidity and overlapping variables in her explanation, but at the moment that contradiction was ignored and we obediently accepted the task.

We read the questions for about five minutes when the semicircle we had formed with our chairs began to lose its shape. While the work of deciding upon answers continued, people got up and walked across the room or leaned to the person to their side for help in figuring out the correct answers. The instruction we received that each question could be classified under only one of the variables was causing difficulties. With her high-pitched voice, Xinia controlled the growing chatter in the room and began the review. She started by reading the first question: "Which of the following statements do you identify with: (a) I prefer not to use condoms; it is uncomfortable; (b) Only if my partner brings a condom do I use it; (c) I always use condoms; (d) No answer." She continued by asking, "How many of you think this question measures attitudes?" Eight people raised their hands. "How many think it is about practices?" Seven people raised their hands. "OK, who thinks it is about knowledge?" No one raised their hand, and eight abstained. People were perplexed by how divided the group was, and before Xinia articulated a response, we all started laughing at the strangeness of our disagreements.

In response, Xinia made a new attempt to explain the methodology, this time using a new triadhead-heart-body - and resorting to the embodied nature of experience. Her logic was that forms of experience can be located in the body itself and that if the integral self was to be made visible, the body could not be ignored. Xinia explained how the variables we had considered so far could be located in different parts of the body. She said, [End Page 232]

Conocimientos are lodged in people's heads. An actitud is a form of anticipation that involves feelings and sensations as well as thinking; it is connected to the heart. A práctica refers to something that actually occurs in a person's life; it involves the body doing something and it occurs in a present that is extended through action.

Despite Xinia's new attempt to clarify CAP, the audience was not refocusing; instead, whispers and puzzled looks dominated the room. At that point, I saw Joaquin move in his chair as if preparing to say something. Indeed, with a playful tone and a loud voice, he took advantage of a pause between sentences and said, "Están trampositas las preguntas, ah?"[These questions are little tricksters, eh?]. Immediately, laughter exploded in the room, creating an impasse that gave Xinia a respite from having to explain the contradictions in her presentation and within CAP more generally. Some people were in tears, while others were grabbing their stomachs trying to soothe the pain from so much laughing. We laughed uncontrollably, and our reservations about the logic of the methodology, about our own intellectual abilities, and about Xinia's expertise were relaxed. With our laughter the mood in the room changed drastically, as if picking up the remnants of the chuckles and smiles that had occurred throughout the whole workshop. Laughter moved us from a tense confusion about the impossibility of keeping the variables independent from each other to a humorous commitment to move forward, embracing our inability to enact CAP's demand for separability and orderly classification.

We continued our review, and Xinia read another of the practice questions, asking how many people thought it was measuring knowledge, attitudes, or practices. The group was again divided 
in three blocks. After about an hour of comments, more explanations, and more laughter, the workshop ended without coming to any resolution of our methodological inconsistencies. We went home knowing that the project was going to continue, that the questionnaires had to be completed, and with the expectation that the value of the questions was the integral, yet at points confusing, depiction of the self they produced.

As ubiquitous as laughter is, it is surprising how seldom it appears in anthropological studies of knowledge, law, and power. In social theory more broadly, laughter is commonly rendered as either a repair mechanism for situations where expectations of social interaction are unmet (Freud 2003) or as a marker of cynicism, distance, and irony (Bakhtin 1984; Sloterdijk 1987; Žižek 2002). Despite their differences, these understandings of laughter take for granted the existence of an external object to which laughter is a reactive mechanism. From these perspectives, Joaquin's joke and our many moments of laughter during the workshop would have been a form of subversion, a challenge to the panoptical nature and postcolonial politics of the project directed at the Spaniards and their attempt to manage our behavior. That was not, however, the reason for our laughter. We laughed at the difficulties of the calculative exercise we were engaged in and at how the blurred boundaries between the variables troubled our own everyday classificatory impulses to create separations. This self-referential form of laughter, which mirrors the circularity of the audit itself and the intensive nature of the whole process, gave us "a sense of emancipation, [End Page 233] consolation and childlike elevation" (Critchley 2002:95). This was laughter without repressive judgment, desire, or aggression, but with an appreciation and elevation of the self. Our laughter did not break our confidence in the audit but allowed us to go forward with the indicators, despite our lack of clarity about what they represented.

The explanation of this type of laughter cannot be found "inside" the subject but has to be placed, as Henri Bergson (2007) suggests, back into its "natural environment": society. For Bergson, society can only be understood in its duration, as an ongoing accomplishment for which there is no end point. Consequently, this audit (and the laughter it engendered) needs to be considered in the duration of time and not as a static condition. At the workshop, our laughter was a punctuation in the duration of our interactions that shifted the logical demands for orderly cohesiveness within our own thought into a more playful and, as such, potentially transformative mode (on the seriousness of humor and the politics of play see Haraway 2003; Jonsson n.d.; Thrift 2007). Laughter allowed us to continue the search for an integral entity despite our difficulties with categories. Laughter was the condition of possibility for new articulations where indicators were used as conveyors of emphasis and not as instruments of exclusion.

\section{Step Three: Interpreting the Scale-Sliding Abilities of Percentages}

Two months after the training workshop where Xinia explained CAP, Joaquin identified a conflict between the methodology and the political objectives of the project. The contradiction had been there all along, but no one had commented on it before. One of the NGOs' strategic motivations for producing an integral depiction was to highlight the simultaneously individual and collective nature of their work. This seemed to be at odds with the "individualist" 
foundations of CAP. In a world where the individual is taken for granted as the receptacle of knowledge, the objective of the project was to increase the visibility of collectives of different shapes and forms (i.e., community NGOs, aqueduct organizations, unions, farmers organizations) and their contributions to water management. Their success in implementing the human right to water as a policy was a collective endeavor to which they contributed not merely as individuals with rights, but through the many forms that their work and their sense of self took. Not surprisingly, AIDE also wanted a story about communities, organizations, and, most desirably, the nation. This fundamental conflict between the individualistic foundations of CAP and their objective of highlighting collective work pushed the project team to incorporate a third triad into the questionnaire: individual-organization-nation.

Veronica and Joaquin communicated to Xinia their reservations about the written questionnaire she had developed and asked for an amendment to the questions. At this point they had reworked the questions many times to make sure that their language and topics coincided with the rationale behind their proposal. This time, Xinia replaced the individual "test" questions about the individual with questions about organizations or about Costa Rica as a nation. Thinking ahead to possible difficulties in the discussion of the results, Xinia also noted in the margin of each question whether it referred to knowledge, attitudes, or practices. [End Page 234]

Joaquin and Veronica sent this revised version of the questionnaire to participants, emphasizing that it was extremely important that they organize a meeting with as many people as possible to produce and submit group responses. Although only ten of the local and grassroots groups involved in the original selection of training topics answered the questionnaires, the documents they submitted embodied more than ten respondents. Joaquin's insistence that the participants answer the questionnaires collectively led to a variety of forms of discussion: in one organization the executive board answered the questions, in another those who happened to be in the office the day before the deadline answered it in yet another the members' assembly provided the answers, and in one case there was a confession that the manager had answered the questionnaire by himself because the deadline had passed and he could not find anyone to help him. The organizers learned about these arrangements during a workshop they convened for a preliminary interpretation of the results.

At that review workshop, about an hour after the scheduled starting time, Veronica and Joaquin began as was usual with a PowerPoint presentation. After several slides, I recognized a pattern: a pie graph showing the percentages and several bullet points explaining the graph. Veronica's charismatic personality brought the PowerPoint to life, yet after only five slides I began to drift and speculate about how she would make the leap from the small number of organizations that answered the questionnaire to piece together a story about Costa Rica as a nation. I found myself reasoning that if the nation was made up of a large number of people, a large number of responses were needed to make any argument about it valid (see Anderson 1991; Cohn 1996). But my concerns with the number of respondents dissipated as soon as I refocused on the types of discussions we were having and saw people navigate scales from the individual to the organization and the nation without tripping on the divisions between them. In our discussions, organizations had feelings and the nation held knowledge as easily as individuals had attitudes or engaged in practices. Combinations between these triads quickly showed me how, rather than 
delineating scales, the percentages were in fact making overlaps and blurred boundaries speakable. One example will clarify the fluidity with which we slid from one scale to another.

Continuing with her presentation, Veronica read question number 28, "Water is a public good means (mark the correct answers)..." and then told us that 80 percent of the Costa Rican organizations agreed that water was a public good. The pie graph showed 80 percent of its volume colored in a light purple (agreed) and only 20 percent in a darker burgundy (disagreed). During the discussion of this question, Carlos, the union representative I had spoken to about numbers in a previous meeting, expressed his preoccupation with the consequences of this finding. He argued that even though 80 percent of the nation could recognize that statement, we could not assume that the nation as a whole knew exactly what it meant, and it was necessary to include radio spots in the training program to make the nation understand what is a public good. At this point, the audience suggested ideas to deal with this situation, all directed to the nation and not to the ten organizations that the percentages represented. Without any impediment, our findings were projected to the knowledge the nation had, regardless of the "small" number of organizations to which the graph referred. The responses of ten organizations were seamlessly interpreted as providing a picture of the nation. [End Page 235] One after another, in our discussion, all of the answers were in fact opportunities to index different scales and domains of experience simultaneously.

Anthropologist Jane Guyer suggests that numeric scales, such as percentages, "contain the conceptual 'hooks' that link one scale to another, without reducing them to a common denominator" (2004:49). Percentages worked in this case less as hooks and more like spaces where different spheres of political action overlapped. The percentage, like laughter, revealed an uncanny capacity to make a conversation about one domain turn into another without erasing or overemphasizing the distinction between the two and without making the shift problematic (Verran 2010). It became a conduit to name a sense of continuity between domains that are often concealed as residual in the articulation and display of forms of political being (Sørensen 2003:55). The indicators smoothly enrolled multiple scales as if the specific variable or scale being measured - the individual, the organization, or the nation - was somewhat irrelevant because the indicator inevitably carried over the other scales into the conversation. Rather than trimming complexity to simplify a sense of self and make it quantifiable, as auditing techniques commonly do, percentages allowed those involved to think in terms of intensity rather than exclusion (DeLanda 2002; Sørensen 2003), thereby intensifying the reference to one variable without implying that it could be isolated from other domains. After the workshop ended, I approached Carlos again and asked whether he was pleased with the numbers that we had produced. He indeed was because, as he put it, "these numbers show everything at the same time" (San Jose Costa Rica, April 25, 2008). These specific numbers could hold experiences, body parts, and political scales of action at once, instead of making them alternative orders of analysis. Not surprisingly, I initially thought of these utterances as flawed conclusions, but after hearing many iterations of this combinatorial logic and talking to people like Carlos, I realized that we were involved in an exercise of qualitative integration. The nation could be the individual, and the organization could be the nation as well as the individual. The richness of the indicators, I finally understood, was this ability to make the overlap between the elements in these triads speakable through each other. 
As I have shown, these creative and seriously political combinations occurred before the telos of the auditing project was accomplished. The audit was most lively during the design and making of the instrument itself, when Joaquin and colleagues were busy refracting their ideas about who they were and what they did, and before the final percentages and graphs were written down and sent to the funding agency. During that time, after the project had started but before the results were produced, these numeric indicators were not limited to retrospective representations. Numbers spoke about experimental imaginations of the self that transgressed the limitations that evaluating capacity building as a function of knowledge acquisition poses for collectives that want to vindicate their own contributions to water management and policy making. Although inscribed in inequitable political economies and postcolonial relations, this transparency-creation project cannot be automatically reduced to a disciplining tool of neoliberal governance, as audit cultures literatures often suggest (Kipinis 2008). Through a series of strategic decisions and humorous moments, the audit stopped being an instrument to represent what is taken for granted and became an opportunity [End Page 236] to map and name that which remains outside the realms of normalized political visibility: the simultaneity of domains as political possibilities.

\section{Conclusion}

Through CAP, my colleagues in the field associated domains of experience (knowledge, attitudes, and practices), body parts (head, heart, body), and scales of political action (individual, organization, nation) to create an "integral" picture of the self that is collective, bodily, and political. What is remarkable about this project is how explicit the method for describing that integral political entity was. The motivation to do the audit themselves, a combination of a desire to control the story coming out of the audit and to keep project dollars among the participating organizations, allowed a circular arrangement that completely changed the qualitative nature of the audit into an experimental exploration. In the audit's duration, this exploration relied, on the one hand, on the ability to laugh as a way to recognize and embrace nonexclusionary categories as CAP originally asked for, and, on the other hand, on the use of percentages as numeric devices to allow for the combination of asymmetric domains and their simultaneous consideration. Attention to the making of the audit, with a focus on process, rather than on its outcome or its effects, sheds light into the multiple and unexpected qualities of widespread knowledge-making practices such as the production of indicators.

If in this article I had focused on the effects of the audit after the results were delivered to the funding agency, these creative and politically significant engagements would have been rendered invisible. Because the political self is not an end point and politics are never finalized, paying more attention to the making, rather than the effects, of transparency projects provides a renewed understanding of the political possibilities that people find in neoliberal technologies such as transparency-creation mechanisms. It is not without irony that audit techniques, framed under liberal rationalities of the individual, make the excesses of such inventions more apparent. Or, perhaps it is only natural that they come across more forcefully in those instances, and what is ironic is the lack of attention that scholars have ascribed to it. This other life of transparency is playful although structured, intentional although uncontrollable, and strategic although slippery. 
This liveliness is the product of knowledge-making practices that open possibilities to reinvent political subjectivities during the "in-between" temporality of regulatory and normative work and not as its ulterior effect. [End Page 237]

Notes: Research for this article was generously funded by the Wenner Gren Foundation, the National Science Foundation, the University of California, Irvine. I want to thank Bill Maurer, Carol Greenhouse, Gemma John, Amy Levine, Leticia Barrera, Robert Werth, and Dawn Nafus for their thoughtful comments and help in developing the ideas behind this article. Four anonymous reviewers also helped me streamline my argument and make it more precise. 


\section{References Cited}

Anderson, Benedict 1991 Imagined Communities: Reflections on the Origins and Spread of Nationalism. London: Verso.

Bakhtin, Mikhail 1984 Rabelais and His World. Hélène Iswolsky, transl. Bloomington: Indiana University Press.

Bergson, Henri 2007 Laughter: An Essay on the Meaning of the Comic. Cloudesley Brereton and Fred Rothwell, transl. London: Dodo Press.

Bessire, Dominique 2005 Transparency: A Two-Way Mirror? International Journal of Social Economics 32(2):424-438.

Burger, Ronelle \& Trudy Owens, 2010 Promoting Transparency in the NGO Sector: Examining the Availability and Reliability of Self-Reported Data. World Development 38(9):1263-1277.

Cohn, Bernard 1996 Colonialism and its Forms of Knowledge: the British in India. Princeton: Princeton University Press.

Critchley, Simon 2002 On Humour. London: Routledge.

DeLanda, Manuel 2002 Intensive Science and Virtual Philosophy. London: Continuum.

Deleuze, Gilles, and Felix Guattari 1987 A Thousand Plateaus: Capitalism and Schizophrenia. Minneapolis: University of Minnesota Press.

Florini, Ann 2007 Introduction: The Battle over Transparency. In The Right to Know: Transparency for an Open World. A. Florini, ed. Pp. 1-18. New York: Columbia University Press.

Foucault, Michel 1980 The Confession of the Flesh (interview). In Power/Knowledge: Selected Interviews and Other Writings 1972-1977. C. Gordon, ed. Pp. 194-228. Brighton, UK: Harvester Press.

Freud, Sigmund 2003 The Joke and its Relation to the Unconscious. James Strachey, transl. New York: Penguin Books.

Gaonkar, Dilip Parameshwar, and Robert J. McCarthy, Jr. 1994 Panopticism and Publicity: Bentham's Quest for Transparency. Public Culture 6(3):547-575.

Garsten, Christina, and Monica Lindh de Montoya 2008 Transparency in a New Global Order: Unveiling Organizational Visions. Cheltenham, UK: Edward Elgar. 
Gray, Rob 2002 The Social Accounting Project and Accounting Organizations and Society: Privileging Engagement, Imaginings, New Accountings and Pragmatism over Critique? Accounting, Organizations and Society 27(7):687-708.

Grosz, Elizabeth 2004 The Nick of Time: Politics, Evolution, and the Untimely. Durham: Duke University Press.

Guyer, Jane I. 2004 Marginal Gains: Monetary Transactions in Atlantic Africa. Chicago: University of Chicago Press.

Guyer, Jane I. et al . (14 coauthors) 2010 Introduction: Number as Inventive Frontier. Anthropological Theory 10(1-2):36-61.

Haraway, Donna 2003 The Companion Species Manifesto: Dogs, People and Significant Otherness. Chicago: Prickly Paradigm Press.

Hetherington, Kregg 2011 Guerrilla Auditors: The Politics of Transparency in Neoliberal Paraguay. Durham: Duke University Press.

Hull, Matthew S. 2008 Ruled by Records: The expropriation of Land and the Misappropriation of Lists in Islamabad. American Ethnologist 35(4):501-518.

Humphrey, Caroline 2008 Reassembling Individual Subjects. Anthropological Theory 8(4):357380.

Jonsson, Hjorleifur n.d. Losing the Remote: Representation and Harm in Anthropology: School of Human Evolution and Social Change. Arizona State University.

Kipinis, Andrew B. 2008 Audit Cultures: Neoliberal Governmentality, Socialist Legacy, or Technologies of Governing? American Ethnologist 35(2):275-289.

Latour, Bruno 1990 Drawing Things Together. In Representation in Scientific Practice. Michael Lynch and Steve Woolgar, eds. Pp. 19-68. Cambridge: MIT Press.

Li, Fabiana 2009 Documenting Accountability: Environmental Impact Assessment in a Peruvian Mining Project. PoLAR: Political and Legal Anthropology Review 32(2):218-236.

Lury, Celia 1998 Prosthetic Culture: Photography, Memory and Identity. London: Routledge.

MacPherson, C.B. 1962 The Political Theory of Possessive Individualism: Hobbes to Locke. Oxford: Oxford University Press.

Mathews, Andrew S. 2011 Instituting Nature: Authority, Expertise and Power in Mexican Forests. Cambridge: MIT Press. 
Maurer, Bill 2005 Mutual Life Limited: Islamic Banking, Alternative Currencies, Lateral Reason. Princeton: Princeton University Press.

Merry, Sally Engle 2011 Measuring the World: Indicators, Human Rights, and Global Governance. Current Anthropology 52(S3):S83-S95.

Murray Li, Tania 2009 The Law of the Project: Government and 'Good Governance' at the World Bank in Indonesia. In Rules of Law and Laws of Ruling: On the Governance of Law. Franz von Benda-Beckman, Keebet von Benda-Beckman, and Julia Eckert, eds. Pp. 237-256. Burlington: Ashgate.

Nelson, Diane M. 2010 Reckoning the After/Math of War in Guatemala. Anthropological Theory 10(1-2):87-95.

Porter, Theodore M. 1995 Trust in Numbers: The Pursuit of Objectivity in Science and Public Life. Princeton: Princeton University Press.

Prat, Andrea 2005 The Wrong Kind of Transparency. The American Economic Review 95(3):862-877.

Reed, Adam 1999 Anticipating Individuals: Modes of Vision and Their Social Consequence in a Papua New Guinean Prison. The Journal of the Royal Anthropological Institute 5(1):43-56.

Rheinberger, Hans-Jorg 1997 Toward a History of Epistemic Things: Synthesizing Proteins in the Test Tube. Stanford: Stanford University Press.

Riles, Annelise 2005 New Agenda for the Cultural Study of Law: Taking on the Technicalities. Buffalo Law Review 53:973-1034.

Roberts, John 2009 No One is Perfect: The Limits of Transparency and an Ethic for 'Intelligent' Accountability. Accounting, Organizations and Society 34(8):957-970.

Rojas Moncada, Varinia, and Jorge Mora Portuguez 2007 Plan de Formación y Generación de Capacidades sobre Manejo Comunitario del Agua en Centro America.

Shearer, Teri 2002 Ethics and Accountability: from the For-Itself to the For-the-Other. Accounting, Organizations and Society 27(6):541-573.

Shore, Cris 2008 Audit Culture and Illiberal Governance: Universities and the Politics of Accountability. Anthropological Theory 8(3):278-298.

Sloterdijk, Peter 1987 Critique of Cynical Reason. Michael Eldred, transl. Minneapolis: University of Minnesota Press.

Sørensen, Bent Meier 2003 Gilles Deleuze and the Intensification of Social Theory. Ephemera 3(1):50-58. 
Strathern, Marilyn 2000 Introduction: New Accountabilities. In Audit Cultures: Anthropological Studies in Accountability, Ethics, and the Academy. Marilyn Strathern, ed. Pp. 1-18. London: Routledge.

Strathern, Marilyn 2004 The Whole Person and Its Artifacts. Annual Review of Anthropology 33:1-19.

Thrift, Nigel 2007 Non-Representational Theory: Space, Politics, Affect. New York: Routledge.

Toms, Steven 2010 Calculating Profit: A historical Perspective on the Development of Capitalism. Accounting, Organizations and Society 35:205-221.

Vaivio, J. 2006 The accounting of "The Meeting": Examining Calculability within a "Fluid" Local space. Accounting, Organizations and Society 31(8):735-762.

Valverde, Mariana 2009 Jurisdiction and Scale: Legal 'Technicalities' as Resources for Theory. Social and Legal Studies 18(2):139-157.

Verran, Helen 2001 Science and African Logic. Chicago: University of Chicago Press.

Verran, Helen 2010 Number as an Inventive Frontier in Knowing and Working Australia's Water Resources. Anthropological Theory 10(1-2):171-178.

von Benda-Beckman, Franz, Keebet von Benda-Beckman, and Julia Eckert, eds. 2009 Rules of Law and Laws of Ruling: On the Governance of Law. Burlington: Ashgate.

West, Harry G., and Todd Sanders, eds. 2003 Transparency and Conspiracy. Durham: Duke University Press.

Žižek, Slavoj 2002 The Sublime Object of Ideology. London: Verso. 